\title{
Powieść mashupowa jako współczesny kulturowo- -literacki miszmasz, czyli dlaczego wiktoriańskie powieści nawiedziły zombie, wilkołaki i wampiry
}

\author{
Abstract \\ Novel-as-Mashup, Contemporary Cultural-Literary Remix. Why Zombie, \\ Werewolves and Vampires Populate Victorian Novels?
}

The following article aims to expound the phenomenon of parodical genre of literary mashups (or novels-as-mashups). This recent pop-cultural trend, initiated by Seth Grahame-Smith and Quirk Classics' series Pride and Prejudice and Zombies, has witnessed numerous followers and generated a new type of projected reader. This controversial, verging on plagiarism collaborative endeavour pairs contemporary writers and the authors of (mainly Victorian) classics. However, the latter's participation is of posthumous nature. The following literary and cultural phenomenon has large intermedial potential, since several mashups have recently welcomed film adaptations. The main objective is to discuss the definition and typology of mashups, the origins of this pop-cultural phenomenon, its genological hybridity, commercial success, projected readers' competences as well as ensuing nostalgic and ironic implications of literary mashups.

Keywords: novel-as-mashup, zombie fiction, warewolf fiction, vampire fiction, prosumer culture, neo-Victorianism, parodical retellings of classics

Słowa kluczowe: powieść mashupowa, powieść zombijna, powieść wilkołacza, powieść wampiryczna, kultura prosumencka, neowiktorianizm, parodystyczne wersje powieści klasycznych

\section{Wprowadzenie}

Parodystyczne przeróbki i trawestacje dzieł literackich to nihil novi w czasach post- i neomodernizmu, natomiast powieść typu mashup jest stosunkowo nowym zjawiskiem w literaturze i kulturze popularnej kształtującym na nowo interakcję 
autora kodującego i czytelnika dekodującego ${ }^{1}$. Hybrydyczny gatunek powieści mashupowej powstał z połączenia dwóch, trzech wyraźnie identyfikowalnych elementów takich sformalizowanych gatunków, jak powieść obyczajowa, popular fiction oraz horror. Takie zestawienie konkretnych, acz kontrastujących, składników ma na celu wywołanie efektu humorystycznego, dlatego też występują w niej elementy łagodnej satyry. Istotą literackiego mashupu jest parodystyczne popkulturowe opracowanie kanonicznej powieści obyczajowej odwołującej się głównie do epoki wiktoriańskiej i okresu regencji. Powieść mashupowa ma charakter delikatnie subwersywny z uwagi na wpisaną weń automatyczną ironię. Choć ślady mashupowych eksperymentów odnajdziemy już w powieści Anno Dracula Kima Newmana² z 1992 roku, za prekursora tej formy można uznać Nicka Mamatesa, który w roku 2005 wydał powieść Move Under Ground ${ }^{3}$, wykorzystując w niej mitologię stworzoną przez Lovecrafta. Jednakże sama powieść napisana jest językiem stylizowanym na twórczość Jacka Kerouaca, słynnego pisarza pokolenia bitników, którego uczynił głównym bohaterem ${ }^{4}$. Choć Move Under Ground nie odniosła spektakularnego sukcesu i nie znalazła miejsca w mini kanonie mash-upowych powieści, z pewnością zainicjowała modę na tego typu literackie „składanki” lub remiksy. Fenomen mashupów literackich jest utożsamiany głównie z Sethem Grahamem-Smithem, amerykańskim autorem absurdalnych poradników oraz serią wydawniczą Quirk Classics, która ukazała się nakładem wydawnictwa Quirk Books ${ }^{5}$ w latach 2009-2011. Niemal natychmiast zyskała liczne grono naśladowców, w tym okresie ukazało się ponad 30 gatunkowo różnorodnych powieści typu mashup nawiązujących do epoki wiktoriańskiej i okresu regencji. Zdaniem autorki artykułu należałoby je sklasyfikować odpowiednio jako: ,powieść typu mashup i zombi”, ,powieść typu mashup i wampiry” oraz „,powieść typu mashup i wilkołaki”. Do pierwszej kategorii przynależą między innymi Pride and Prejudice and Zombies ${ }^{6}$, prequel Pride and Prejudice and Zombies: Dawn of the Dreadfuls ${ }^{7}$ oraz sequel Pride and Prejudice and Zombies: Dreadfully Ever After ${ }^{8}$, Alice in Zombieland ${ }^{9}$, I am Scrooge: A Zombie Story for

${ }^{1}$ Ten typ powieści badano w różnych kręgach kulturowych. Najsilniej rezonuje on w Wielkiej Brytanii, szczególnie Walii, gdzie zagadnieniem zajmują się Megen de Bruin-Molé (2017, 2019), Marie Louise Kohlke, Ann Heilmann i Mark Llewellyn (2016). Z kolei w Niemczech badają je Eckart Voigts-Virchow (2012) oraz Tim Lanzendörfer (2018). We Francji natomiast Christian Gutleben (2017). Na polskim gruncie o zjawisku wspomina Ryszard Knapek (2012).

2 K. Newman, Anno Dracula, London 1992.

${ }^{3}$ N. Mamates, Move Under Ground, New York 2005.

${ }^{4}$ Chcąc ocalić ludzkość przed upadkiem, powieściowy pisarz wyrusza w podróż z przyjaciółmi awangardystami: Nealem Cassadym i Williamem S. Burroughsem. Podobnie jak Keruac, Mamates wybiera formułę powieści drogi.

${ }^{5}$ Amerykańskie wydawnictwo Quirk Books, które już pierwszym członem nazwy konotuje odmienność, dziwactwo czy odmienioną klasykę z elementami zombie.

${ }^{6}$ S. Grahame-Smith, J. Austen, Pride and Prejudice and Zombies, Philadelphia, PA 2009.

${ }^{7}$ S. Hockensmith, Pride and Prejudice and Zombies: Dawn of the Dreadfuls, Philadelphia, PA 2010.

${ }^{8}$ S. Hockensmith, Pride and Prejudice and Zombies: Dreadfully Ever After, Philadelphia, PA 2010.

${ }^{9}$ L. Carroll, N. Cook, Alice in Zombieland, Chicago, IL 2011. 
Christmas $^{10}$ czy Grave Expectations ${ }^{11}$. Do drugiej kategorii przypiszemy Little Vampire Women ${ }^{12}$, Jane Slayre ${ }^{13}$, Wuthering Bites ${ }^{14}$, Heathcliff: Vampire of Wuthering Heights ${ }^{15}$ czy Romeo and Juliet and Vampires ${ }^{16}$. Do trzeciej natomiast, najwęższej, należą już tylko Little Women and Warewolves ${ }^{17}$ oraz Emma and the Warewolves ${ }^{18}$ czy Robinson Crusoe: The Eerie Adventures of the Lycanthrope Roberto Clinesa ${ }^{19}$. Ponadto w tym czasie ukazały się Sense and Sensibility and Sea Monsters $^{20}$, Android Karenina ${ }^{21}$ czy Mansfield Park and the Mummies ${ }^{22}$. Na gruncie rodzimym zabieg wplecenia w dzieło kanonu lektur wątków fantastycznych wykorzystał Kamil Śmiałkowski, wzbogacając Przedwiośnie Żeromskiego o motywy zombie i wydając w 2010 roku Przedwiośnie żywych trupów ${ }^{23}$. Podobne działania na tekstach kanonicznych wykonywali twórcy literatury elektronicznej (np. remiksy utworów Brunona Schulza autorstwa Leszka Onaka). Powieści, takie jak Abraham Lincoln: Vampire Hunter ${ }^{24}$, Queen Victoria: Demon Hunter ${ }^{25}$ czy Paul is Undead: The British Zombie Invasion ${ }^{26}$, należałoby sklasyfikować jako odrębny, biofikcyjny wariant mashupu, nie zaś jako powieść typu mashup, jak proponuje Eckart Voigts-Virchow ${ }^{27}$.

Celem niniejszego artykułu jest przybliżenie polskiemu badaczowi fenomenu powieści typu mashup, który silnie rezonuje w kulturze popularnej i jest coraz szerzej badany, głównie w Wielkiej Brytanii. W dalszej części skoncentruję się kolejno na: genezie tego wariantu powieści, jej hybrydycznej naturze i gatunkowej nieokreśloności, komercyjnym aspekcie oraz projektowanym odbiorcy. Ponadto omówimy ideowy wymiar mashupu, a także wpisane weń aspekty nostalgii, ironii i kampowości.

10 A. Roberts, Ch. Dickens, I Am Scrooge: A Zombie Story for Christmas, London 2009.

11 Ch. Dickens, S. Browning, Grave Expectations: The Classic Tale of Love, Ambition, and Howling at the Moon, London 2011.

12 L. Messina, L. May. Alcott, Little Vampire Women, London 2010.

13 E. Sherri Browning, E. Brontë, Jane Slayre, New York 2010.

14 S. Gray, E. Brontë, Wuthering Bites, New York 2010.

15 A. Paris, Heathcliff: Vampire of Wuthering Heights, Scotts Valley, CA 2010.

16 C. Gabel, Rome and Juliet and Vampires, London 2010.

17 P. Grand, L.M. Alcott, Little Women and Werevolves, New York 2010.

18 A. Rann, J. Austen, Emma and the Werewolves: Jane Austen's Classis Novel with Blood-Curdling Lycanthropy, New York 2009.

19 P. Clines, H.P. Lovecraft, D. Defoe, Robinson Crusoe: The Eerie Adventures of the Lycanthrope, New York, 2009. Powieść wzbogacona o wilkołaki, ale także potwory z uniwersum Lovecrafta.

20 J. Austen, B.H. Winters, Sense and Sensibility and Sea Monsters, Philadelphia, PA 2009. Powieść nawiązuje do legend o potworach morskich.

21 B.H. Winters, L. Tolstoy, Android Karenina, Philadelphia, PA 2010. Steampunk, podgatunek cyberpunka.

22 Powieść, w której jako element fantastyczny pojawiają się mumie.

23 K. Śmiałkowski, Przedwiośnie żywych trupów, Warszawa 2010.

24 S. Grahame-Smith, Abraham Lincoln: Vampire Hunter, New York 2011.

25 A.E. Moorat, Queen Victoria: Demon Hunter, London 2010.

26 A. Goldsher, Paul is Undead: The British Zombie Invasion, New York 2010.

27 Por. E. Voigts-Virchow, Pride and Promiscuity and Zombies, or: Miss Austen Mashed up in the Affinity Spaces of Participatory Culture [w:] Adaptation and Cultural Appropriation: Literature, Film, and the Arts, ed. N. Pascal, O. Lindner, Berlin 2012, p. 43-56. 


\section{Geneza powieści typu mashup}

Termin ukuła Caroline Kellogg ${ }^{28}$, dziennikarka „Los Angeles Times”, w swojej recenzji Pride and Prejudice and Zombies. Choć początkowo zaklasyfikowała ten tekst jako ,,parodię" i „literacką hybrydę”, zmieniła go później na ,,powieść typu mashup" (novel-as-mashup), który to termin przyjął się w dyskusji dotyczącej kultury remiksu, badań poświęconych adaptacji bądź neowiktorianizmowi czy schyłkowemu okresowi postmodernizmu. Warto jednak podkreślić, że hybrydyczny charakter oraz parodystyczna relacja, w jaką tekst późniejszy wchodzi z pierwotnym zostały trafnie uchwycone przez Kellogg jako kwintesencja

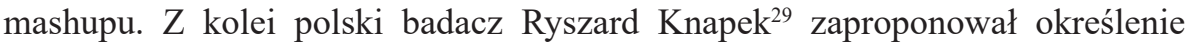
„(p)opracowanie", które oddaje charakter nietypowej odsłony tekstów klasycznych w ramach serii książek Quirk Classics $^{30}$. Z tego też względu parodystyczne popkulturowe opracowanie, rzeczywiście wpisujące się w idee mashupów, wydaje się bardziej adekwatne niż użyte anglojęzyczne określenie „,nowa rozszerzona wersja".

Mashup odwołuje się wprawdzie do korzeni muzycznych, jednakże niesłusznie wywodzi się jego genezę z samej muzyki, zapominając, że nowożytna sztuka podejmowała eksperymenty z taką formą znacznie wcześniej. Przecież już dadaiści i surrealiści eksperymentowali z wizerunkiem Mona Lisy pod koniec XIX wieku. Obecnie utożsamiany jest z trendem w literaturze i kulturze popularnej, który zakłada korzystanie z oryginalnego tekstu ad libitum, lecz tak, by nie zatrzeć jego odrębności i by dla czytelnika jako użytkownika kultury widoczny był kolaboracyjny aspekt dzieła. Wpisuje się on poniekąd w założenia literatury remiksowej, gdzie remiks to kolaż, który powstaje z połączenia fragmentów dwóch lub więcej tekstów, poetyk i frazeologii: „Słowo jest samplem, struktura zdania sekcją rytmiczną, autor - didżejem skreczującym dobrane przez siebie utwory" ${ }^{\prime 31}$. Taka praktyka literacka zachęca do korzystania z utworów dostępnych w domenie publicznej oraz opublikowanych na wolnych licencjach - nie chronionych już prawami autorskimi. Określenia literacki mashup czy też miszmasz, wydają się tyleż nietrafione, ile nieprecyzyjne w przeciwieństwie do muzycznego wzorca, ponieważ w literackim wariancie mashupu nie występują dwa równorzędne utwory stworzone wcześniej. Mamy natomiast do czynienia z tekstem będącym nieznacznym (od 5 do 50 procent) ${ }^{32}$ uzupełnieniem utworu pierwotnego. Jako że

${ }^{28}$ C. Kellog, Pride and Prejudice and Zombies, https://www.latimes.com/entertainment/la-etzombies4-2009apr04-story.html (dostęp: 10.04.2019).

${ }^{29}$ R. Knapek, Kultura zombie-tekstualna (o „Quirk Books” na przykładzie Dumy i uprzedzenia i zombi), „Świat i Słowo" 2012, t. 1 (18), s. 91-101.

${ }^{30} \mathrm{~W}$ anglojęzycznych powieściach mashupowych „specjalizują się" przede wszystkim wydawnictwa amerykańskie. Oprócz sztandarowego Quirk Books są to między innymi Gallery Books, Permuted Press czy Sourcebooks. W Wielkiej Brytanii zaś Harper Collins, Gollancz oraz Titan Books, a w Kanadzie Book*hug Press.

${ }^{31}$ Fundacja Liternet, https://fakty.interia.pl/kultura/news-zremiksuj-literature-zostan-literackim-didzejem,nId,894832 (dostęp: 15.05.2019).

${ }^{32}$ M. de Bruin Molé, Gothic Remixed: Monster Mashups and Frankenfictions in $21^{\text {st-Century }}$ Culture, London 2020, p. 3. 
dobór tekstów jest w obu przypadkach uwarunkowany kwestią praw autorskich, na okładkach wyodrębnia się zarówno autora remiksu, jak i utworu klasycznego. W tekście Mariusza Pisarskiego czytamy:

Gdyby tak postacie umarłych na równi z żyjącymi i w swoich remiksach wyraźnie zaznaczyć, gdzie jestem ja, a gdzie klasyk, możemy dokonać pewnej zmiany jakościowej. Postmodernistyczny kolonializm ustąpi miejsca neowiktoriańskiej, manufakturalnej kolaboracji. Nieżyjący autor, zepchnięty do domeny publicznej, zaczyna wracać do życia, staje się naszym aktywnym współpracownikiem, ożywiamy go niczym przy wywoływaniu duchów i sadzamy przy własnym biesiadnym stole mikserskim. Pewnej sprawiedliwości staje się zadość ${ }^{33}$.

Powyższy cytat brzmi niczym manifest remiksologów i akcentuje kolaboratywny aspekt remiksów literackich, w których ożywia się dzieło i postać nieżyjącego autora jako współtwórcę literackiego przedsięwzięcia. „Kolaboracja” wydaje się jednak w tym kontekście szczególnie problematyczna, ponieważ trudno mówić o aspekcie kolaboratywnym czy współpracy w przypadku nieżyjącego autora. Powieść mashupową należałoby raczej oceniać w kategorii nadużycia czy wręcz plagiatu.

\section{Gatunkowa hybrydyczność}

Trudności klasyfikacyjne tego literackiego „,bękarta” wynikają z jego hybrydyczności, mianowicie dość zaskakującego połączenia dwóch popularnych gatunków: powieści i horroru. Współcześni autorzy sięgający do literackiej klasyki, połączyli (typowe dla postmodernistycznych i neomodernistycznych eksperymentów) alternatywne przedstawienie rzeczywistości z treściami i toposem popularnego nurtu powieści o wampirach, wilkołakach i zombie wraz z elementami innych gatunków, między innymi gore czy cyberpunk w powieści obyczajowej. Zdaniem Voights-Virchowa powieść oraz zombie fiction ,[...] dwa antytetyczne, wyraźnie nacechowane, genologicznie skrystalizowane gatunki [...] najlepiej reprezentuje słowo ,versus" [na przykład]: kanon Austen versus kanon zombie"34.

W przypadku mashupu podstawowym literackim źródłem odniesienia i inspiracji jest wiek XIX, epoka wiktoriańska oraz okres regencji, głównie w Wielkiej Brytanii. Drugim źródłem inspiracji są postaci historyczne, stąd wspomniany już gatunek mashupu typu biofiction. Kolejny typ to miszmasz (czyli kombinacja trzech utworów), czego przykładem będzie Robinson Crusoe: The Eerie Adventures of the Lycanthrope ${ }^{35}$, która łączy w sobie trzy elementy: powieść macierzystą, elementy $\mathrm{z}$ utworów Lovecrafta oraz gatunek powieści wilkołaczej. Z tego też

33 M. Pisarski, Wywotywanie duchów, czyli druga strona remiksu, http://www.ha.art.pl/ felietony/745-mariusz-pisarski-wywolywanie-duchow-czyli-druga-strona-remiksu.html (dostęp: 15.05.2019).

34, ,...] two antithetical, distinctly marked, generically crystalized genres [...] best represented by the 'vs.' [e.g.] the Austen canon vs. Zombie canon”. E. Voights-Virchow, op. cit., p. 51.

35 R. Clines, op. cit. 
względu na okładce wyodrębniono nazwiska trzech autorów: Defoe, Lovecrafta i Clines'a.

W przeciwieństwie do innych postmodernistycznych współczesnych wersji powieści kanonicznych, które eksperymentują z formą i stylem, w powieści typu mashup brak zabiegów transformacyjno-reinterpretacyjnych. Mamy przede wszystkim do czynienia z uzupełnieniem i wzbogaceniem na poziomie fabularno-stylistycznym. Mashup zachowuje podstawowy ciąg fabularny, dodając jedynie nowe wątki i elementy fabularne i wzbogacając pierwotne właściwości bohaterów. Towarzyszy temu imitacja stylistyczna i składniowa, co przejawia się wprowadzeniem nieznacznych modyfikacji przy jednoczesnym tworzeniu zupełnie nowego tekstu bądź przywłaszczeniem zdań (niemal) w całości. Nowy materiał może zatem stanowić 5 procent pierwotnego tekstu (Mansfield Park: The Wild and Wanton Edition ${ }^{36}$ ) lub 40 procent (Sense and Sensibility and Sea Monsters ${ }^{37}$ ). De Bruin-Molé proces zawłaszczenia określa mianem ,kanibalizacji”, a sam wytwór kultury współczesnej „frankensteinowskim” z uwagi na to, że jako twór „powieściopodobny” - trudno go bowiem rozpatrywać w kategorii literackości - częstokroć wywołuje u czytelnika dezorientację ${ }^{38}$. Voigts-Virchow określa to jako „tekstualny promiskuityzm”39. Genologiczny bagaż mashupu oscyluje między różnymi odczytaniami oraz implikacjami zarówno literatury epoki wiktoriańskiej, jak i dyskursu XXI wieku, ponieważ bezpośrednio łączy z sobą teksty dziewiętnastowieczne i postmodernistyczne figury oraz formy, tworząc $\mathrm{w}$ ten sposób połączenia tyleż zaskakujące, ile często prowizoryczne ${ }^{40}$. Tak rozumiany mashup otwiera się na odmienność, heterogeniczność czy hybrydyczność, gdyż częstokroć łączy w sobie steampunk oraz retrowiktorianizm; ma przy tym duży potencjał intermedialny.

Nowy trend w literaturze spotkał się z mieszanym przyjęciem wśród krytyków. Gutenleben określił mashup mianem „,nostalgicznego postmodernizmu”41 i jednocześnie fazy kulturalnego regresu, która cechuje schyłkowy okres postmodernizmu ${ }^{42}$. Zdaniem Megen de Bruin-Molé wyróżnia go odejście od awangardowej ironii właściwej dla mainstreamowego postmodernizmu ${ }^{43}$. Niewątpliwie błędne jest założenie, że powieść typu mashup wykazuje cechy powieści neowiktoriańskiej. O ile mashup zawiera właściwe dla niej metatekstualne odniesienia i stanowi formę przywłaszczenia utworu klasycznego, o tyle balan-

${ }^{36}$ N. Mitchell, J. Austen, Mansfield Park: The Wild and Wanton Edition, Avon, MA 2013.

37 J. Austen, B.H. Winters, op. cit.

${ }^{38}$ M. de Bruin-Molé, Now with Ultraviolent Zombie Mayhem!: The Neo-Victorian novel-as-mashup and the limits of postmodern irony [w:] Neo-Victorian Humour: The Rhetorics and Politics of Comedy, Irony and Parody, ed. M.L. Kohlke, Ch. Gutleben, Amsterdam 2017, p. 24; por. A. Riter, Dead and Alive: Austen's Role in Mashup Literature [w:] Jane Austen and Philosophy, ed. M. Marinucci, London 2016; T. Lanzendörfer, Books of the Dead: Reading Zombie in Contemporary Literature, Mississippi 2018.

${ }^{39}$ E. Voigts-Virchow, op. cit., p. 51.

${ }^{40}$ Ibid., p. 24.

${ }^{41}$ Ch. Gutleben, Nostalgic Postmodernism: The Victorian Tradition and the Contemporary British Novel, Amsterdam-New York 2001, p. 5.

${ }^{42}$ Ibid., p. 120.

${ }_{43}^{43}$ M. de Bruin-Molé, op. cit., p. 3. 
suje na granicy plagiatu. Ponadto samo odniesienie do XIX wieku, epoki wiktoriańskiej czy regencji nie czyni automatycznie mashupu neowiktoriańskim. Poza tym literacki mashup jako eksperyment $\mathrm{z}$ formą powieści i treścią nie musi wcale oznaczać śmierci postmodernizmu, a jedynie jego schyłkowy okres, szczególnie w kontekście gier parodystycznych z utworami kanonicznymi, który to trend zdominował kilka ostatnich dekad. Jak bowiem zauważa de Bruin-Molé fragmentaryczność i brak określonej formy historiograficznej metafikcji, do której można by gatunkowo przypisać mashupy, otwiera przestrzeń do niespotykanych połączeń $^{44}$.

\section{Aspekt komercyjny i projektowany odbiorca}

Jak słusznie zawyrokowała krytyczka „New York Times” Jennifer Schuessler, jest to najbardziej skuteczna i dochodowa formuła ${ }^{45}$. Autorzy mashupów kierują się nie tylko rozpoznawalnością czy sentymentem, ale przede wszystkim namacalnym komercyjnym sukcesem dzieł klasyki literatury, które doczekały się popularnych adaptacji. Paradoksalnie częstotliwość odniesień do utworu Pride and Prejudice dotyczy bardziej adaptacji właśnie niżeli tekstów. Nie dziwi więc, że siłą napędową tego gatunku są względy praktyczne i komercyjne. Z jednej strony powieść typu mashup zbija kapitał na wiktoriańskim sentymencie i może się wydawać chłodną finansową kalkulacją wydawcy i autora, który przynależy do kultury prosumenckiej, a wiec jest zarazem wydawcą (producentem) i konsumentem literatury. $Z$ drugiej zaś ta nowa forma wyrazu właściwa dla kultury remiksu może przekonać do siebie sceptyków, jeśli przeanalizujemy jej główne założenia: dekonstrukcję (nie)lubianych lektur z kanonu, przełamanie schematów interpretacji dzieła czy odrzucenie ,postmodernistycznego kolonializmu” na rzecz współdziałania.

Jeśli chodzi o cele, przykładowo misją wydawnictwa Quirk Books, wydającego ,zremiksowaną klasykę literatury” jest „wzbogacenie klasycznych powieści o zjawiska kultury popularnej" ${ }^{46}$ i zdrową dawkę absurdu oraz spopularyzowanie klasycznych dzieł Jane Austen wśród młodych czytelników, którym ta seria jest dedykowana. Choć, jak słusznie zauważa Ryszard Knapek, popularyzowanie sprowadza się do „lektury mimochodem”, mashup należałoby raczej rozpatrywać w kategoriach powierzchownej parodii, która - w przeciwieństwie do mainstreamowych praktyk postmodernistycznych - nie eksperymentuje z formą i stylem. Przełamuje natomiast schematy interpretacyjne dzieła oraz dekonstruuje (nie)lubiane utwory z kanonu lektur, budując przy tym ,zdrowy dystans do śmiertelnej powagi" tekstu pierwotnego ${ }^{47}$.

44 Ibid., p. 24.

45 J. Schuessler, Undead-Austen Mash-Ups, „New York Times”, 13 December 2009. https:// archive.nytimes.com/query.nytimes.com/gst/fullpage9E05E3DC1E39F930A25751C1A96F9C8B63. html (dostęp: 20.05.2019).

${ }^{46}$ „To enhance classic novels with pop culture phenomena”; ,remixed classics”. Quirk Books, https://www.quirkbooks.com/page/quirk-classics (dostęp: 10.05.2019).

${ }^{47}$ R. Knapek, op. cit., p. 92. 
Komercyjny aspekt ilustrują dwie strategie wydawnicze. Quirk Books promuje swoją serię Pride and Prejudice and Zombies na trzy sposoby: jako „,nową zuchwałą wersję”, ,reanimację Austen” bądź ,,wersję wzbogaconą o nowe sceny miażdżenia kości w zombijskim chaosie"48. O ile przymiotnik ,zuchwała” konotuje dość niejednoznaczny stosunek do naśladowanego tekstu, o tyle nie jest on hołdowniczy, negujący czy kontestujący, jak w przypadku rewizjonizmu historycznego bądź kulturowego. Jednocześnie reanimacja może sugerować próbę odrestaurowania narracyjnych i stylistycznych konwencji powieści obyczajowej. Najbardziej jednak wybrzmiewa kolejna strategia promocyjna, a mianowicie łączenie z sobą elementów pierwotnych oraz nowych.

Tabela 1

\begin{tabular}{|l|l|}
\hline \multicolumn{1}{|c|}{ Quirk Classics } & \multicolumn{1}{c|}{ Tlumaczenie } \\
\hline $\begin{array}{l}\text { Complete with romance, heartbreak, martial } \\
\text { arts, cannibalism, and an army of shambling } \\
\text { corpses. } \\
\text { (Pride and Prejudice and Zombies: } \\
\text { Dreadfully Ever After) }\end{array}$ & $\begin{array}{l}\text { Kompilacja romansu, zawodu miłosnego, } \\
\text { sztuk walki, kanibalizmu oraz armii } \\
\text { powłóczących nogami trupów. }\end{array}$ \\
\hline $\begin{array}{l}\text { Complete with romance, heartbreak, } \\
\text { swordfights, cannibalism, and thousands } \\
\text { of rotting corpses. } \\
\text { (Pride and Prejudice and Zombies) }\end{array}$ & $\begin{array}{l}\text { Kompilacja romansu, zawodu miłosnego, } \\
\text { walki na miecze, kanibalizmu oraz tysięcy } \\
\text { gnijących trupów. }\end{array}$ \\
\hline $\begin{array}{l}\text { Complete with romance, action, comedy, } \\
\text { and an army of shambling corpses. } \\
\text { (Pride and Prejudice and Zombies: Dawn of } \\
\text { the Dreadfuls) }\end{array}$ & $\begin{array}{l}\text { Kompilacja romansu, komedii akcji oraz } \\
\text { armii powłóczących nogami trupów. }\end{array}$ \\
\hline $\begin{array}{l}\text { This masterful portrait of Regency } \\
\text { England blends Jane Austen's biting social } \\
\text { commentary with ultraviolent depictions of } \\
\text { sea monsters biting. }\end{array}$ & $\begin{array}{l}\text { Ten mistrzowski portret Anglii okresu } \\
\text { A new tale of romance, heartbreak, and } \\
\text { tentacle mayhem. } \\
\text { (Sense and Sensibility and Sea Monstiwy komentarz społeczny }\end{array}$ \\
\hline $\begin{array}{l}\text { Filled with the same blend of romance, } \\
\text { drama and fantasy that made the first two } \\
\text { Quirk Classics "New York Times” best } \\
\text { sellers. } \\
\text { (Android Karenina) }\end{array}$ & $\begin{array}{l}\text { kąresych potworów morskich. } \\
\text { Wypełniona tą samą mieszanką romansu, } \\
\text { pierwsze mashupy klasyki literatury - } \\
\text { bestselery „New York Times”. }\end{array}$ \\
\hline
\end{tabular}

Źródło: opracowanie własne (tłum. K.Sz.).

Jak pokazują powyższe przykłady zaczerpnięte z okładek mashupów Quirk Books, w każdym z opisów zaakcentowana jest kompilacja lub łączenie dwóch

48 „Audacious retelling”; ,all new scenes of bone-crunching zombie mayhem”; ,reanimated Austen". Quirk Books, https://www.quirkbooks.com/book/pride-and-prejudice-and-zombies (dostęp: 10.05.2019). 
typów składników cechujących tekst pierwotny oraz nowych elementów. Wydawcy przyjęli identyczną formułę dla serii Pride and Prejudice and Zombies, zmieniając jedynie dobór składników. W przypadku zaś Sense and Sensibility and Sea Monsters, kolejnej zmashupowanej powieści Austen, nawiązanie do strategii łączenie przeciwstawnych elementów jest wyrażone wprost, choć formuła jest nieco inna. Android Karenina stara się swoim opisem nawiązywać do serii wydawniczej.

Z kolei Permuted Press oraz Ballantine Books przyjęły zgoła odmienną strategię i promują swoje mashupy jako rzekomo zaginioną wersję, która w pierwszym przypadku pochodzi z autentycznych dzienników i wspomnień rozbitka i zawieruszyła się wśród dokumentów Lovecrafta. W drugim zaś nieocenzurowaną wersja Little Women, którą współcześnie odkrył autor mashupu, zaludniają wilkołaki.

Tabela 2

\begin{tabular}{|c|c|}
\hline Quirk Classics & Przekład własny \\
\hline $\begin{array}{l}\text { Recently discovered amidst the papers of } \\
\text { the } 20^{\text {th }} \text {-century writer and historian H.P. } \\
\text { Lovecraft is what claims to be the true } \\
\text { story of Robinson Crusoe. Taken from the } \\
\text { castaway's own journals and memoirs, and } \\
\text { fact-checked by Lovecraft himself, it is free } \\
\text { from many of Defoe's edits and alterations. } \\
\text { From Lovecraft's work a much smoother, } \\
\text { simpler tale emerges - but also a far more } \\
\text { disturbing one. } \\
\text { [Robinson Crusoe: The Eerie Adventures of } \\
\text { Lycanthrope }]\end{array}$ & $\begin{array}{l}\text { [Dzieło] odnalezione niedawno pośród } \\
\text { dokumentów dwudziestowiecznego pisarza } \\
\text { i historyka H.P. Lovecrafta uważa się za } \\
\text { prawdziwą historię Robinsona Crusoe. Zo- } \\
\text { stała zaczerpnięta z autentycznych dzienni- } \\
\text { ków i wspomnień rozbitka, a faktograficznie } \\
\text { zweryfikował ją zaś sam Lovecraft. Nie za- } \\
\text { wiera przeróbek ani edytorskich poprawek. } \\
\text { Z dzieła Lovecrafta wyłania się uproszczo- } \\
\text { na, bardziej przejrzysta, ale i mroczniejsza, } \\
\text { wersja. }\end{array}$ \\
\hline $\begin{array}{l}\text { Little Women is a timeless classic. But } \\
\text { Louisa May Alcott's first draft - before } \\
\text { her editor sunk his teeth into it - was even } \\
\text { better. Now the original text has at last } \\
\text { been exhumed. In this uncensored version, } \\
\text { the March girls learn some biting lessons, } \\
\text { transforming from wild girls into little } \\
\text { women - just as their friends and neighbours } \\
\text { transform into vicious, bloodthirsty } \\
\text { werewolves! } \\
\text { [Little Women and Werewolves] }\end{array}$ & $\begin{array}{l}\text { Małe kobietki to ponadczasowe dzieło } \\
\text { klasyki literatury. Jednakże pierwszy szkic } \\
\text { Louisy May Alcott był o niebo lepszy, } \\
\text { zanim wydawca wbił w niego swoje kły. } \\
\text { Nareszcie odgrzebano ten pierwotny tekst. } \\
\text { W tej nieocenzurowanej wersji nieokrzesane } \\
\text { i dzikie siostry March pobierają lekcje } \\
\text { gryzienia i przeobrażają się w małe kobietki, } \\
\text { podczas gdy ich sąsiedzi przechodzą } \\
\text { przemianę w zawistne, żądne krwi } \\
\text { wilkołaki. }\end{array}$ \\
\hline
\end{tabular}

Źródło: opracowanie własne (tłum. K.Sz.).

Bardzo istotnym elementem jest tu także ,projektowany odbiorca” mashupów, którego profil stworzył Ryszard Knapek. Jak zauważa badacz, czytelnik tego typu tekstów przyzwyczajony jest do określonej, dość specyficznej estetyki ukształtowanej głównie na kinie akcji, ale także fantastyce. Oczekuje więc szybszych zwrotów akcji i gwałtownych emocji. Taki typ tekstu i odbiorcy wpisuje się w my- 
ślenie „reformacyjne”, który z jednej strony przeciwstawia się konserwatywnej postawie polegającej na reifikowaniu tekstów literackiego kanonu, z drugiej zaś przedkłada potrzebę dość swobodnie pojętego uwspółcześnienia i „przystosowania do współczesnego odbiorcy" nad zagrożenia plagiatu czy profanacji dzieł uznanych autorów. Konsekwencją tego jest obranie drogi quasi-edukacyjnej oraz zabieg „przysposobienia” dzieła do odbiorcy i jego „warunków poznawczych”49.

\section{Nostalgia, ironia i kampowość mashupów}

Kulturowy potencjał powieść typu mashup rozpatruje się także w kontekście badań nad neowiktorianizmemi i postmodernizmem. Dyskusja toczy się głównie wokół etyki, roli autora w poststrukturalizmie XXI wieku, roli projektowanego odbiorcy, kampowości, a przede wszystkim granic nostalgii i ironii. Jak zauważa de Bruin-Molé, ironia, parodia oraz nostalgia tworzą istotne „ramy koncepcyjne ilustrujące to jak przeszłość jest używana (i nadużywana) w teraźniejszości”" ${ }^{50}$. Zdaniem Gutlebena komercyjny sukces powieści retrowiktoriańskich i neowiktoriańskich idzie $\mathrm{w}$ parze $\mathrm{z}$ nostalgicznym postmodernizmem. Jego zdaniem mashupy należałoby jednak rozpatrywać w kategorii literackich ekstremów postmodernizmu, które wpisują się w regresyjny, nie progresyjny charakter kultury masowej. Jako wytwór kultury masowej mashupy nie tylko ironicznie traktują teksty kanoniczne, w formie alternatywnych, parodystycznych odczytań, ale także zgłębiają formę, funkcje oraz granice współczesnej ironii ${ }^{51}$. Choć przeszłość stanowi źródło inspiracji, mashupy nie są nostalgiczne, ponieważ intencją autorów nie jest sentymentalizowanie lub aktualizowanie przeszłości. Powieści typu mashup grają natomiast sentymentem, zbijając kapitał na nostalgii wobec epoki wiktoriańskiej i okresu regencji oraz twórczości Jane Austen, umniejszając zarazem wartości jej dzieł. Odwołują się do rozpoznawalności dzieła, projektowanego odbiorcę zachęca z kolei do przyjęcia ironicznego dystansu i podjęcia gry, tak by lektura była rozrywką.

Warto nadmienić w tym kontekście, że katalizatorem zmian i procesów w kulturze i literaturze jest często nonsens, za sprawą którego niezamierzone znaczenie zostaje wpisane lub wczytane w akt komunikacji. Zdaniem Lindy Hutcheon w postmodernistyczną ironię wpisany jest aspekt nostalgii, choć paradoksalnie mamy do czynienia z jednoczesnym ironizowaniem samej nostalgii i pragnieniem spojrzenia wstecz w poszukiwaniu autentyczności ${ }^{52}$.

Kampowość, kolejna cecha i współczesna estetyka eksponująca sztuczność stanowi nieodłączny element współczesności i wytwór kultury masowej. Mashup przynależy do świata kampu poprzez epatowanie celowym okropieństwem. We-

${ }^{49}$ R. Knapek, op. cit., s. 94.

50 "[...] irony, parody, and nostalgia have each served an important conceptual frameworks for illustrating the way the past is used (and abused) in the present". M. de Bruin-Molé, op. cit., p. 5 .

${ }^{51}$ Ibid.

${ }^{52}$ L. Hutcheon, M.J. Valdés, Irony, Nostalgia, and the Postmodern: A Dialogue, „Poligrafias” 2000,3 , p. 34. 
dług Stephena Linsteada mashup „,...] wdraża oburzający/skandalizujący kicz wraz z automatyczną ironią po to by skierować uwagę na sztuczność granic"53. Kampowość mashupów przejawia się także w tym, że choć nie przeciwstawiają się kulturze i literaturze wysokiej, ich stosunek do dzieła pierwotnego jest jednak kontestujący. Wspomniana automatyczna ironia stanowi natomiast oznakę łagodnej drwiny względem przetworzonego materiału.

\section{Ideowy wymiar mashupów}

Główny wymiar ideowy dotyczy symbolicznego przeniesienia znaczeń. W literackich mashupach dominujący temat - czy to romantyczny, czy społeczny - zostaje zastąpiony nowym, co bezpośrednio wiąże się ze wzrostem poziomu brutalności $\mathrm{w}$ tego typu powieści. Przemoc, którą epatują teksty, powiązana jest z niechęcią, a niekiedy wręcz nienawiścią do Innego. Przykładem takiego przeniesienia jest zastąpienie odmieńca czy odszczepieńca Innym (na przykład zombie - potworami morskimi, wampirami czy też wilkołakami), który funkcjonuje jako odmieniec (homo sacer), lecz w wymiarze fantastycznym. Jak zauważa Knapek, funkcję nieumarłych należałoby rozpatrywać w kontekście kultury mieszczańskiej i intepretować jako „rekompensat[ę] dla thumionej nienawiści do Innego" ${ }^{54}$. Jest to bowiem relacja oparta na przemocy, tym bardziej że zombie, podobnie jak inne twory, pozbawione są umiejętności komunikowania się. Zombie jest zatem „fantazmatem liberalnego mieszczaństwa, który pozwala bezkarnie mordować" zarówno odmieńców, jak i wszystkich Innych o wyższym statusie społecznym „,eniących sobie spokój oraz nienaruszalność swojej przestrzeni i własności”. W owej mieszczańskiej kulturze popularnej zombie funkcjonuje więc jako substytut „bezdomnych, imigrantów, odmiennych rasowo" ${ }^{\text {. }}$.

\section{Wnioski}

Jako że w ostatnich latach powieść typu mashup stanowiła popularny obiekt badań komparatystycznych, stała się przez to dookreślona i skonwencjonalizowana nie tylko genologicznie. Mimo swojego (kontrowersyjnego) kolaboratywnego charakteru krytycy oceniają ją nie tylko pod kątem walorów literackich, ale przede wszystkim jako przywłaszczenie, rodzaj „kanibalizacji” czy „frankensteinizacji” tekstu bądź tekstualnego promiskuityzmu. Niewątpliwie do powstania literackiego mashupu przyczyniła się równoległa popularność zombie fiction czy powieści wilkołaczej i wampirycznej, generując przy okazji nowy typ odbiorcy o odmiennych kompetencjach popkulturowych, zanurzonego w ontologicznie odrębnych światach alternatywnych i fantastycznych. Projektowany odbiorca traktuje

${ }^{53},,[. .$.$] deploys outrageous kitsch with reflexive irony in order to draw attention to the artifici-$ ality of boundaries”. S. Linstead, Organizational Kitsch, „Organization” 2002, 9 (4), p. 666.

${ }^{54}$ R. Knapek, op. cit., s. 96.

${ }^{55}$ Ibid., s. 100. 
mashupy jako podszytą ironią lekkostrawną popkulturową rozrywkę, w którą wpisana jest eskapistyczna nostalgia. Przy okazji mamy w tym przypadku do czynienia z przysposobieniem dzieła do poznawczych warunków projektowanego odbiorcy. Fakt, że powieść typu mashup funkcjonuje na pograniczu popularnych gatunków - powieści i horroru - niesie z sobą istotne implikacje. Charakter powieści zmienia się na mniej subwersywny, operujący kliszami, co bardziej współgra z powierzchowną parodią (spłycającą jej polityczną i społeczne rezonowanie). Staje się zatem bardziej lekturą mimochodem niż popularyzowaniem klasyki sensu stricto.

Jest to niewątpliwy fenomen na mapie popkulturowych i postmodernistycznych eksperymentów z dużym potencjałem intermedialnym, mashup bowiem funkcjonuje równolegle w innych mediach, czego dowodem są liczne filmowe adaptacje, które rezonują popkulturowo bardziej niż same teksty typu mashup.

\section{Bibliografia}

Austen J., Winters B.H., Sense and Sensibility and Sea Monsters, Philadelphia, PA 2009. Brontë Ch., Browning Erwin S., Jane Slayre, New York 2010.

Bruin-Molé M. de, Gothic Remixed: Monster Mashups and Frankenfictions in $21^{\text {st }}$ -Century Culture, London 2020.

Bruin-Molé M. de, "Now with Ultraviolent Zombie Mayhem!": The Neo-Victorian novel-as-mashup and the limits of postmodern irony [w:] Neo-Victorian Humour: The Rhetorics and Politics of Comedy, Irony and Parody, ed. M. Kohlke, Ch. Gutleben, Amsterdam 2017, p. 249-276.

Carroll L., Cook N., Alice in Zombieland, Chicago, IL 2011.

Clines P., Defoe D., Lovecraft H.P., Robinson Crusoe: The Eerie Adventures of the Lycanthrope, New York 2009.

Czolgosz W.B., Twain M., The Adventures of Huckleberry Finn and Zombie Jim, London 2011.

Dickens Ch., Browning Erwin S., Grave Expectations:The Classic Tale of Love, Ambition, and Howling at the Moon, London 2011.

Fundacja Liternet: https://fakty.interia.pl/kultura/news-zremiksuj-literature-zostan-literackim-didzejem,nId,894832 (dostęp: 15.05. 2019).

Gabel C., Rome and Juliet and Vampires, London 2010.

Goldsher A., Paul is Undead: The British Zombie Invasion, New York 2010.

Grahame-Smith S., Abraham Lincoln: Vampire Hunter, New York 2011.

Grahame-Smith S., Austen J., Pride and Prejudice and Zombies, Philadelphia, PA 2009.

Grand P., Alcott L.M., Little Women and Werevolves, New York 2010.

Gray S., Brontë E., Wuthering Bites, New York 2010.

Gutleben Ch., Nostalgic Postmodernism: The Victorian Tradition and the Contemporary British Novel, Amsterdam-New York 2001.

Gutleben Ch., Kohlke M.-L., Neo-Victorian Humour: Comic Subversions and Unlaughter in Contemporary Historical Re-Visions, Amsterdam 2017.

Heilmann A., Llewellyn A.M., Neo-Victorianism: The Victorians in the Twenty-First Century, 1999-2009, London 2016. 
Hockensmith S., Pride and Prejudice and Zombies: Dawn of the Dreadfuls, Philadelphia, PA 2010.

Hockensmith S., Pride and Prejudice and Zombies: Dreadfully Ever After, Philadelphia, PA 2010.

Hutcheon L., Valdés M.J., Irony, Nostalgia, and the Postmodern: A Dialogue, ,Poligrafias" 2000, t. 3, p. 29-54.

Kellog C., Pride and Prejudice and Zombies, https://www.latimes.com/entertainment/la-et-zombies4-2009apr04-story.html (dostęp: 10.04.2019).

Knapek R., Kultura zombie-tekstualna (o ,Quirk Books” na przykładzie Dumy i uprzedzenia i zombi), „Świat i Słowo” 2012, t. 1(18), s. 91-101.

Lanzendorfer T., Books of the Dead: Reading Zombie in Contemporary Literature, Mississippi 2018.

Lindstead S., Organizational Kitch, “Organization” 2002, t. 9 (4), p. 657-682.

Mamates N., Move Under Ground, New York 2005.

Messina L., Alcott L.M., Little Vampire Women, London 2010.

Mitchell N., Jane Austen, Mansfield Park: The Wild and Wanton Edition, Avon, MA 2013.

Moorat A.E., Queen Victoria: Demon Hunter, London 2010.

Newman K., Anno Dracula, London 1992.

Paris A., Heathcliff: Vampire of Wuthering Heights, Scotts Valley, CA 2010.

Pisarski M., Wywotywanie duchów, czyli druga strona remiksu, http://www.ha.art.pl/ felietony/745-mariusz-pisarski-wywolywanie-duchow-czyli-druga-strona-remiksu.html (dostęp: 15.05. 2019).

Rann A., Austen J., Emma and the Werewolves: Jane Austen's Classis Novel with Blood-curdling Lycanthropy, New York 2009.

Riter A., Dead and Alive: Austen's Role in Mashup Literature [w:] Jane Austen and Philosophy, ed. M. Marinucci, London 2016.

Roberts A., Dickens Ch., I Am Scrooge: A Zombie Story for Christmas, London 2009.

Schuessler J., Undead-Austen Mash-Ups, „New York Times”, 13 December 2009. https://archive.nytimes.com/query.nytimes.com/gst/fullpage-9E05E3DC1E39F930A25751C1A96F9C8B63.html (dostęp: 9.02.2020).

Śmiałkowski K., Przedwiośnie żywych trupów, Warszawa 2010.

Voigts-Virchow E., Pride and Promiscuity and Zombies, or: Miss Austen Mashed Up in the Affinity Spaces of Partcipatory Culture [w:] Adaptation and Cultural Appropriation: Literature, Film, and the Arts, ed. N. Pascal, O. Lindner, Berlin 2012, p. 43-56.

Winters B.H., Tolstoy L., Android Karenina, Philadelphia, PA 2010. 